\title{
PENGARUH STRATEGI KONFLIK KOGNITIF TERHADAP PENGUASAAN KONSEP PADA MATERI FLUIDA SISWA SMAN 3 MATARAM TAHUN AJARAN 2016/2017
}

\author{
Raehana Tuqalby, Sutrio, Gunawan \\ Program Studi Pendidikan Fisika \\ FKIP, Universitas Mataram \\ Jalan Majapahit No. 62, Mataram \\ E-Mail: Raehanatuqalby15@gmail.com
}

\begin{abstract}
This study aims to determine the effect of cognitive conflict strategy on the mastery of the concept of student fluid material SMAN 3 Mataram academic year 2016/2017. This research is a quasi experimental research using untreated control group design with pretest and posttest. The population in this study is all students of class XI IPA SMAN 3 Mataram. Research sampling using cluster random sampling technique, so selected class XI IPA 1 as experiment class that will be given treatment in the form of cognitive conflict strategy and class XI IPA 2 as control class to be given treatment in the form of conventional instruction (direct instruction). Concept master data collection is done by multiple choice test. Hypothesis test using tpooled variance test. Increased concept mastery is determined based on the results of the N-gain test. The result of the research shows that there is an increase of mastery of student concept in both classes. The experimental class experienced a higher conception mastery than the control class except on the viscosity material. Material of continuity equation in experiment class has the highest increase. This suggests that the cognitive conflict strategy applied successfully increases the mastery of students' concepts in physics learning.
\end{abstract}

Keywords: Cognitive conflict strategy, Mastery of Physics Concept.

\section{PENDAHULUAN}

Pendidikan dilaksanakan dengan tujuan untuk mempersiapkan siswa agar mampu bersaing dalam kehidupan bermasyarakat. Pendidikan di dalam sekolah memiliki peran yang sangat penting untuk mempersiapkan siswa sebaik-baiknya. Terkait dengan perkembangan zaman, pendidikan haruslah mampu memfasilitasi siswa untuk dapat bersaing sesuai dengan perkembangan zamannya.

Menurut Trianto (2011) IPA adalah ilmu pengetahuan yang mempelajari gejala-gejala melalui serangkaian proses yang dikenal dengan proses ilmiah, yang dibangun atas dasar sikap ilmiah dan hasilnya terwujud sebagai produk ilmiah yang tersusun atas tiga komponen terpenting, berup konsep, prinsip dan teori yang berlaku secara umum. Penguasaan konsep fisika merupakan salah satu aspek dalam mengukur hasil belajar siswa yang didapat guna mewujudkan pembelajaran (Sugiana et al, 2016). Gunawan et al (2014) menyatakan bahwa "beberapa konsep fisika termasuk konsep yang abstrak". Konsep fisika yang abstrak sering kali menjadi kendala bagi guru dalam menyampaikan materi kepada siswa, sehingga siswa belum optimal dalam memahami konsep yang dijelaskan guru. Hal ini tentunya berdampak pada minat belajar siswa dalam menerima pelajaran fisika yang menyebabkan rendahnya penguasaan konsep siswa untuk menyelesaikan suatu persoalan. Pentingnya seseorang menguasai suatu konsep adalah agar ia mampu berkomunikasi, mengklasifikasikan ide, gagasan atau peristiwa yang dialaminya dalam kehidupan sehari-hari (Suranti et al, 2016).

Berdasarkan hasil observasi dan wawancara dengan siswa dan guru mata pelajaran fisika kelas XI SMAN 3 Mataram, bahwa mata pelajaran fisika sering dianggap sebagai pelajaran yang sulit dan membosankan. Hal ini sejalan dengan pendapat Setyowati, Subali \& Mosik (2011) yang mengatakan bahwa mata pelajaran fisika dirasakan sulit oleh siswa, karena sebagian besar siswa belum mampu menghubungkan antara materi yang dipelajari dengan pengetahuan yang digunakan. Siswa lebih sering langsung menggunakan persamaan matematis tanpa melakukan analisis, menebak rumus yang digunakan dan menghafal contoh soal yang telah dikerjakan untuk mengerjakan soal-soal lain (Kusdiastuti et al, 2016). Masalah ini akan membawa pola pikir siswa 
pada pembelajaran sangat monoton, di samping itu guru dalam proses pembelajaran kurang memperhatikan konsep awal siswa. Siswa beranggapan bahwa apa yang dipelajari tanpa ada arti karena tidak ada kaitannya dengan pembelajaran yang lalu maupun dengan peristiwa yang ada dalam lingkungan mereka. Guru lebih banyak menekankan pembelajaran yang memungkinkan siswa memiliki kemampuan sebatas dapat menjawab soal. Akibatnya, penguasaan konsep siswa menjadi rendah. Kurangnya penguasaan konsep fisika ditunjukkan dengan rendahnya hasil belajar siswa. Hal ini dilihat dari rendahnya rata-rata hasil ulangan akir semester 1 fisika siswa kelas XI IPA tahun ajaran 2016/2017 yang ditunjukkan pada Tabel 1 . berikut.

Tabel 1 Nilai Rata-Rata Ulangan Akhir Fisika

Semester 1 Tahun Pembelajaran 2016/2017

\begin{tabular}{cccc}
\hline No & Kelas & $\begin{array}{l}\text { Nilai } \\
\text { Rata-Rata }\end{array}$ & KKM \\
\hline $\mathbf{1}$ & XI IPA 1 & 69,22 & 77 \\
\hline $\mathbf{2}$ & XI IPA 2 & 70,70 & 77 \\
\hline $\mathbf{3}$ & XI IPA 3 & 48,50 & 77 \\
\hline $\mathbf{4}$ & XI IPA 4 & 66,00 & 77 \\
\hline $\mathbf{5}$ & XI IPA 5 & 60,55 & 77 \\
\hline $\mathbf{6}$ & XI IPA 6 & 58,00 & 77 \\
\hline
\end{tabular}

(Sumber: Waka Kurikulum SMA N 3 Mataram)

Siswa bukanlah kertas kosong yang siap dituliskan apa saja dikarenakan siswa terlebih dahulu sudah memiliki pengetahuannya sendiri sebelum memasuki dunia sekolah. Pengetahuan yang ada di dalam pikiran siswa dikonstruksi berdasarkan pengalaman, pembelajaran yang didapatkan sebelumnya, fenomena-fenomena lingkungan dan lain sebagainya bukan semata-mata diturunkan langsung oleh pendidik. Guru harus dapat mengubah pola pikir lama dalam pembelajaran yang masih bersifat behaviorisme menjadi konstruktivisme. Konstruktivisme sebagai salah satu teori pembelajaran inovatif menempatkan guru sebagai patner kerja siswa dalam proses pembelajaran. Penelitian Akinbobola dan Afolabi (2010), memunculkan bahwa guru fisika harus berusaha untuk menggunakan praktik konstruktivisme melalui pendekatan penemuan dipandu dalam rangka melibatkan siswa dalam kegiatan pemecahan masalah, belajar mandiri, berpikir kritis dan pemahaman, dan pembelajaran kreatif, bukan dalam belajar menghafal dan menghafal.

Berdasarkan kenyataan tersebut di atas, maka perlu dilakukan perbaikan dalam kegiatan pembelajaran agar penguasaan konsep fisika siswa dapat meningkat. Salah satu alternatif pemecahan masalahnya adalah dengan menggunakan strategi konflik kognitif. Menurut Lee et al (2003) strategi konflik kognitif adalah sebuah keadaan dimana siswa merasa adanya ketidakcocokan antara strukur kognitif mereka dengan keadaan lingkungan sekitarnya.

Adapun fase-fase dalam strategi konflik kognitif didasarkan pada pendapat Lee et al (2003) yakni fase permulaan (preliminary stage), fase konflik (conflict stage) dan fase penyelesaian (resolution stage). Melalui strategi konflik kognitif, siswa di hadapkan pada situasi yang bertentangan dengan konsepnya, kemudian di arahkan pada percobaan atau demonstrasi untuk membuktikan kebenaran konsep tersebut. Dalam pembelajaran ini siswa diberikan kesempatan untuk mengungkapkan konsepsinya dan mengkritisi yang berbeda dengan konsepsinya. Rancangan strategi konflik kognitif dapat mengembangkan kemampuan siswa dalam mengkonstruksi perubahan konsep dan menyelesaikan masalah secara ilmiah (Kang et al, 2010). Sehingga akan dapat berdampak pada peningkatan kemampuan penguasaan konsep.

Berdasarkan uraian di atas, peneliti tertarik untuk melakukan penelitian berjudul "Pengaruh Strategi Konflik Kognitif Terhadap Penguasaan Konsep dan Kemampuan Berpikir Kritis Siswa pada Materi Fluida SMAN 3 Mataram Tahun Ajaran 2016/2017".

\section{METODE PENELITIAN}

Jenis penelitian yang digunakan adalah penelitian eksperimen dengan desain untreated control group design with pretest and posttes. Sebelum diberi perlakukan kedua kelompok sampel diberikan tes awal untuk mengukur kondisi awal. Selanjutnya kelas eksperimen diberikan perlakuan dengan strategi konflik kognitif dan kelas kontrol diberi perlakuan berupa model pembelajaran konvensional (direct instruction). Sesudah perlakuan, kedua kelas diberikan tes akhir. 
Dalam penelitian ini ada 3 variabel yaitu variabel bebas yaitu strategi konflik kognitif, variabel terikat yaitu penguasaan konsep, variabel kontrol yaitu materi ajar yang diajarkan, guru yang mengajar, dan instrumen penilaian pada kelas eksperimen dan kontrol. Populasi dalam penelitian ini adalah seluruh siswa kelas XI IPA di SMAN 3 Mataram tahun ajaran 2016/2017 yang berjumlah 6 kelas. Sedangkan sampel adalah bagian dari populasi. Sampel yang digunakan dipilih dengan menggunakan teknik cluster random sampling. Penelitian ini, untuk mengukur penguasaan konsep digunakan tes berupa pilihan ganda sebanyak 26 soal. Sebelumnya tes pilihan ganda di uji validitasnya sehingga diperoleh 26 soal yang valid. Uji $\mathrm{F}$ digunakan untuk mengetahui homogenitas data dan uji normalitas untuk mengetahui apakah data terdistribusi normal atau tidak. Setelah itu, untuk mengetahui peningkatan nilai kedua tes sebelum dan sesudah diberi perlakuan digunakan uji t polled varians.

Selain uji hipotesis, dilakukan juga uji NGain. Sundayana (2014) menyatakan bahwa uji skor gain dilakukan untuk mengetahui seberapa besar peningkatan penguasaan konsep dengan kriteria terlihat pada Tabel 2.

Tabel 2 Interpretasi Skor Gain

\begin{tabular}{lll}
\hline No. & Interval & Kriteria \\
\hline $\mathbf{1}$ & $0,70 \leq \mathrm{g} 1,00$ & Tinggi \\
$\mathbf{2}$ & $0,30 \leq \mathrm{g}<0,70$ & Sedang \\
$\mathbf{3}$ & $0,00<\mathrm{g}<0,30$ & Rendah \\
\hline
\end{tabular}

\section{HASIL DAN PEMBAHASAN}

Berdasarkan ranah yang dinilai, yaitu ranah kognitif, maka kemampuan yang diukur adalah kemampuan kognitif penguasaan konsep siswa. Tes yang diberikan adalah tes tertulis berbentuk pilihan ganda yang terdiri dari 26 soal. Adapun penguasaan konsep siswa sebelum diberikan perlakuan terlihat dari nilai tes awalnya (pre-test), dan penguasaan konsep setelah diberikan perlakuan terlihat dari nilai tes akhir (post-test).

Tes awal dilakukan untuk mengetahui homogenitas serta normalitas sampel Adapun hasil tes awal dapat dilihat pada Gambar 1.

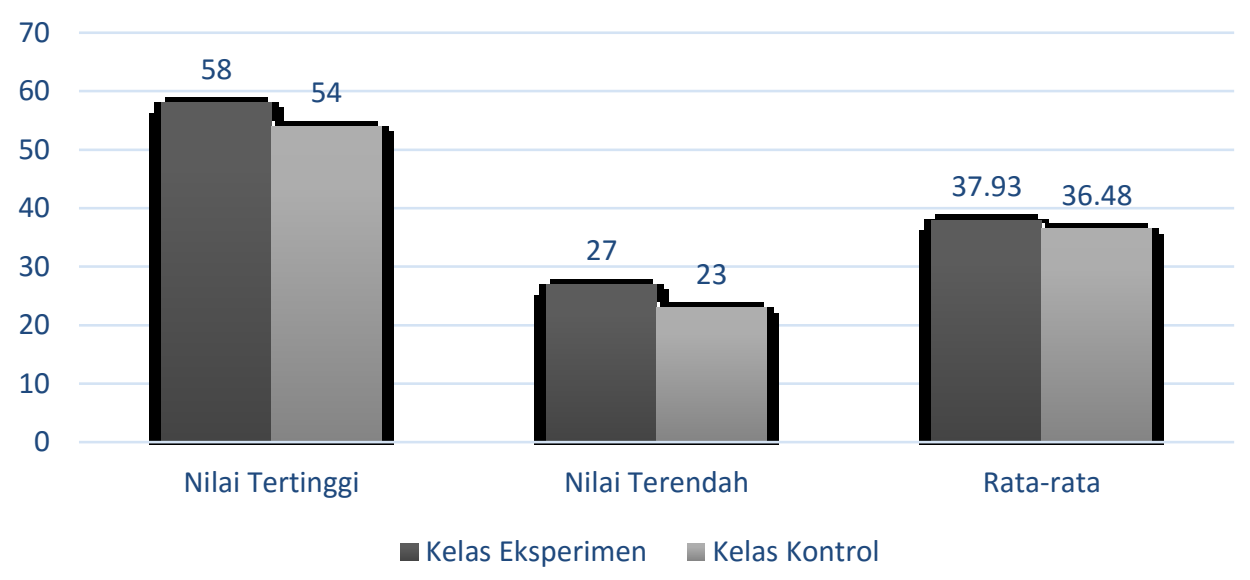

Gambar 1 Perbandingan Hasil Tes Awal Pengusaan Konsep Siswa

Dalam Gambar 1 di atas terlihat bahwa nilai tertinggi untuk kelas eksperimen adalah 58 dan kelas kontrol adalah 54 sedangkan untuk nilai terendah pada kelas eksperimen adalah 27 dan pada kelas kontrol 23. Dengan rata-rata nilai kelas eksperimen 37,93 dan rata-rata nilai kelas kontrol 26,48 .

Data kemampuan akhir yang diperoleh pada penelitian ini adalah data setelah diberikan perlakuan. Tes akhir diberikan untuk mengetahui normalitas dan hipotesis penelitian. Adapun hasil tes akhir dapat dilihat pada Gambar 2. Dalam Gambar 2 di bawah terlihat bahwa nilai tertinggi untuk kelas eksperimen adalah 96 dan kelas kontrol adalah 92 sedangkan untuk nilai terendah pada kelas eksperimen adalah 54 dan pada kelas kontrol 38. Dengan rata-rata nilai kelas eksperimen 76,5dan rata-rata nilai kelas kontrol 67,03. 


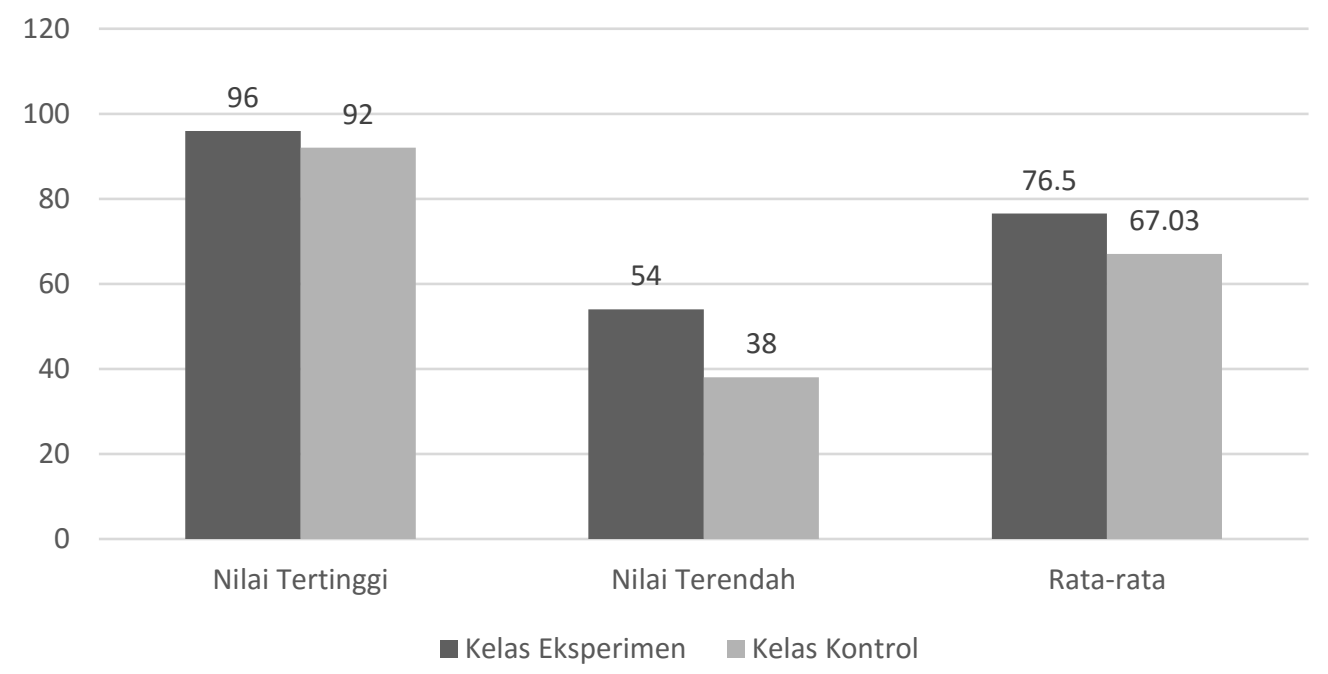

Gambar 2 Perbandingan Hasil Tes Akhir Pengusaan Konsep Siswa

Pengujian data penguasaan konsep siswa untuk kelas eksperimen dan kelas kontrol tes awal dan tes akhir diawali dengan uji homogenitas kedua data, yang dilanjutkan dengan uji normalitas, dan terakhir uji hipotesis menggunakan uji-t polled varians. Dari uji homogenitas data untuk tes awal yang telah dilakukan didapat hasil nilai $F_{\text {hitung }}$ sebesar 1,43 sedangkan nilai $F_{\text {tabel }} 1,77$ dengan taraf signifikan 0,05 . Sehingga $F_{\text {hitung }}<F_{\text {tabel }}$ yang berarti data tes awal kedua kelas adalah homogen.

Selanjutnya dilakukan uji normalitas data tes awal dan tes akhir pada masing-masing kelas. Berdasarkan perhitungan yang telah dlakukan didapatkan hasil bahwa data berdistribusi normal pada tes awal dan tes akhir untuk kelas eksperimen dan kelas kontrol. Untuk tes awal didapatkan nilai $\chi_{\text {hitung }}^{2}$ sebesar 11,76 untuk kelas eksperimen dan 11,81 untuk kelas kontrol. Nilai $\chi_{\text {tabel }}^{2}$ dengan taraf signifikan 0,05 untuk kelas eksperimen dan kelas kontrol sebesar 12,592 untuk. Sehingga dari kedua data tersebut dapat dilihat bahwa $\chi^{2}{ }_{\text {hitung }}<$ $\chi_{\text {tabel }}^{2}$ yang berarti data tes awal untuk kedua kelas berdistribusi normal. Sedangkan untuk tes akhir nilai $\chi^{2}{ }_{\text {hitung }}$ untuk kelas eksperimen sebesar 8,04 dan untuk kelas kontrol sebesar 7,60 Nilai $\chi^{2}{ }_{\text {tabel }}$ dengan taraf signifikan 0,05 untuk kedua kelas adalah 12,592 sehingga data tes akhir kedua kelas terdistribusi normal.

Untuk mengetahui adanya pengaruh strategi konflik kognitif dalam meningkatkan penguasaan konsep siswa dilakukan uji hipotesis. Uji hipotesis menggunakan statistik paramtrik karena data homogen dan terdistribusi normal. Uji hipotesis yang digunakan adalah uji-t polled varians karena sampel pada penelitian ini berbeda $\left(n_{1} \neq n_{2}\right)$. Hasil uji statistik yang dilakukan didapatkan nilai $t_{\text {hitung }}$ sebesar 3,10. Nilai thitung tersebut lebih besar dibandingkan nilai $t_{\text {tabel}}$, yaitu 1,99 pada taraf signifikan 0,05 . Sehingga penggunaan strategi konflik kognitif berpengaruh dalam meningkatkan penguasaan konsep siswa. Penguasaan konsep dapat meningkat melalui strategi konflik kogitif karena siswa di hadapkan langsung pada situasi yang bertentangan dengan konsepnya, kemudian di arahkan pada percobaan atau demonstrasi untuk membuktikan kebenaran konsep tersebut. Dalam pembelajaran ini siswa diberikan kesempatan untuk mengungkapkan konsepsinya dan mengkritisi yang berbeda dengan konsepsinya. Dengan terlibat langsung dalam proses pembelajaran siswa dapat menguasai konsep dengan baik. Hasil ini juga diperkuat dengan hasil-hasil penelitian sebelumnya mengenai strategi konflik kognitif. Setyowati, Subali \& Mosik (2011) menyatakan bahwa konfklik ognitif dalam pembelajaran fisika pada materi tekanan mampu menumbuhkan kemampuan berpikir kritis, penguasaan konsep dan hasil belajar kognitif siswa. Selain itu penelitian Baser (2006) \& Sirait (2012) menyatakan bahwa konflik kognitif dapat meningkatkan penguasaan konsep fisika siswa lebih signifikan dibandingkan dengan model konvensional. Hasil-hasil tersebut memperkuat hasil penelitian ini, yaitu adanya pengaruh strategi konflik kognitif dalam meningkatkan penguasaan konsep siswa. 
Selain melakukan uji hipotesis peneliti juga ingin mengetahui sejauh mana peningkatan yang dialami kedua kelas secara lebih terperinci terkait hubungan nilai kelas kontrol dan kelas eksperimen untuk persentase kenaikan penguasaan konsep setiap sub materi. Perbandingan peningkatan penguasaan konsep per sub materi fluida dalam Gambar 3. Materi fluida terbagi kedalam 6 sub materi yaitu tekanan hidrostatis, hukum pascal, hukum Archimedes, viskositas, persamaan kontinuitas dan asas Bernoulli. Setiap sub materi dianalisis ketercapaiannya berdasarkan perolehan skor tes awal dan tes akhir dan gain ternormalisasi. Perbandingan peningkatan penguasaan konsep per sub materi fluida dalam Gambar 3.

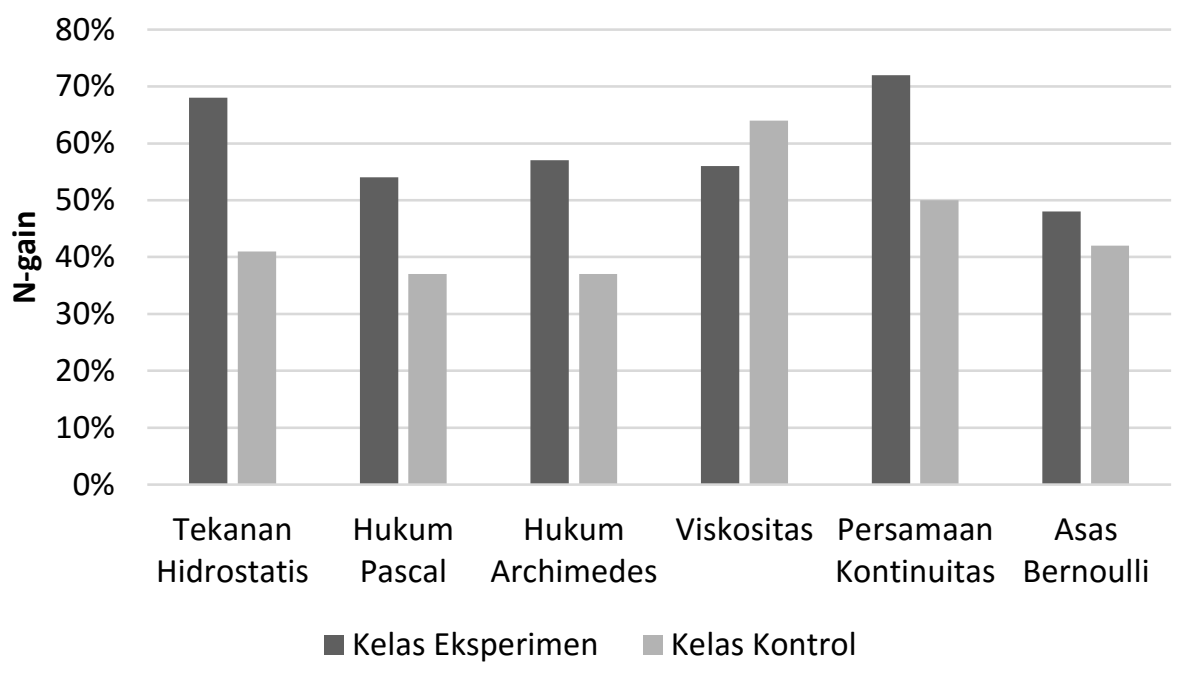

Gambar 3 Perbandingan Nilai N-gain Per Sub Materi

Berdasarkan analisis pada Gambar 3 dapat diketahui bahwa perolehan Persentase $\mathrm{N}$-gain tertinggi kelas eksperimen, yaitu pada sub materi Persamaan kontinuitas $72 \%$ dan terendah sebesar $48 \%$ pada materi asas Bernoulli. Sedangkan pada kelas kontrol $\mathrm{N}$-gain tertinggi adalah $61 \%$ pada sub materi viskositas dan terendah pada sub materi hukum pascal dan hukum Archimedes yaitu 37\%. Terdapat sub materi yang mana kelas kontrolnya lebih tinggi peningkatannya dari kelas eksperimen, yaitu viskositas. Hal ini disebabkan karena soal pada materi tersebut hanya dua dan salah satunya adalah soal hitungan. Pada kelas eksperimen kemampuan untuk menjawab soal hitungan lebih rendah dibandingkan kelas kontrol, karena pada kelas kontrol pada fase pembelajarannya ada pemberian contoh serta latihan soal, sehingga siswa terlatih menjawab soal-soal hitungan. Selain itu, ada faktor eksternal yang tidak bisa peneliti kontrol. Dimana ketika sub materi viskositas jam pelajarannya setelah keluar main, mengakibatkan jam pelajaran agak berkurang karena siswa telat masuk ke dalam kelas. Akibatnya fase penyelesaian atau resolution stage tidak dapat dengan maksimal teraksana. Hal ini tentu berdampak pada penguasaan konsep siswa. Namun, secara rata-rata, peningkatan penguasaan konsep pada kelas eksperimen lebih tinggi dibandingkan kelas kontrol. Dimana pada kelas eksperimen rata-rata peningkatannya sebesar $61 \quad \% \quad$ sedangkan peningkatan kelas kontrol adalah 48\%. Baser (2006) \& Sirait (2012) menyatakan bahwa konflik kognitif dapat meningkatkan penguasaan konsep fisika siswa lebih signifikan dibandingkan dengan model konvensional.

Untuk mengetahui strategi konflik kognitif berpengaruh positif terhadap peningkatan penguasaan konsep siswa dilakukan uji hipotesis berdasarkan skor N-gain. Berdasarkan hasil uji hipotesis berdasarkan skor $\mathrm{N}$-gain didapatkan nilai $t_{\text {hitung }}=2,58$. Nilai $t_{\text {hitung }}$ ini lebih besar dari pada nilai $t_{\text {tabel }}=1,99$. Hal ini berarti bahwa 
strategi konflik kognitif berpengaruh terhadap penguasaan konsep siswa dimana strategi tersebut menyebabkan peningkatan kemampuan berpikir kritis siswa yang positif.

\section{PENUTUP}

Berdasarkan hasil dan pembahasan yang telah dipaparkan dapat disimpulkan bahwa strategi konflik kognitif berpengaruh terhadap penguasaan konsep pada materi fluida sisiwa SMAN 3 Mataram tahun Pelajaran 2016/2017. Adapun saran yang dapat diberikan bagi guru fisika strategi konflik kognitif dapat dijadikan alternatif strategi pembelajaran yang dapat diterapkan dalam mengajar fisika. Namun, dalam penerapannya memerlukan perencanaan dan persiapan yang matang sebelum diterapkan dikelas agar proses pembelajaran dapat berjalan sesuai dengan tujuan pembelajaran yang hendak dicapai. Sedangkan untuk penelitian selanjutnya, strategi konflik kognitif dapat dilakukan pada materi yang berbeda dengan subjek peneliitian yang lebih luas.

\section{REFERENSI}

Akinbobola, A. O., \& Afolabi, F. (2009). Constructivist Practices Through Guided Discovery Approach: The Effect On Students'cognitive Achievements In Nigerian Senior Secondary School Physics. Bulgarian Journal of Science \& Education Policy, 3(2), 223-252.

Baser, M. (2006). Fostering conceptual change by cognitive conflict based instruction on students' understanding of heat and temperature concepts. Eurasia Journal of Mathematics, Science and Technology Education, 2(2), 96-114.

Gunawan, G., Setiawan, A., \& Widyantoro, D. H. (2014). Model Virtual Laboratory Fisika Modern untuk Meningkatkan Keterampilan Generik Sains Calon Guru. Jurnal Pendidikan dan Pembelajaran (JPP), 20(1), 25-32.

Kang, H., Scharmann, L. C., Kang, S., \& Noh, T. (2010). Cognitive conflict and situational interest as factors influencing conceptual change. International Journal of
Environmental and Science Education, 5(4), 383-405.

Kusdiastuti, M., Harjono, A., Sahidu, H., \& Gunawan, G. (2016). Pengaruh Model Pembelajaran Inkuiri Berbantuan Laboratorium Virtual Terhadap Penguasaan Konsep Fisika Peserta Didik. Jurnal Pendidikan Fisika dan Teknologi, 2(3), 116122.

Lee, G., Kwon, J., Park, S. S., Kim, J. W., Kwon, H. G., \& Park, H. K. (2003). Development of an instrument for measuring cognitive conflict in secondary level science classes. Journal of research in science teaching, 40(6), 585-603.

Setyowati, A., \& Subali, B. (2011). Implementasi pendekatan konflik kognitif dalam pembelajaran fisika untuk menumbuhkan kemampuan berpikir kritis siswa SMP kelas VIII. Jurnal Pendidikan Fisika Indonesia, 7(2), 89-96.

Sirait, J. (2012). Pendekatan Pembelajaran Konflik Kognitif Untuk Meningkatkan Penguasaan Konsep Siswa SMA pada Topik Suhu dan Kalor. Jurnal Pendidikan Matematika dan IPA, l(2).

Sugiana, I. N., Harjono, A., Sahidu, H., \& Gunawan, G. (2016). Pengaruh Model Pembelajaran Generatif Berbantuan Media Laboratorium Virtual Terhadap Penguasaan Konsep Fisika Siswa pada Materi Momentum dan Impuls. Jurnal Pendidikan Fisika dan Teknologi, 2(2), 61-65.

Sundayana, R. 2014. Statistika Penelitian Pendidikan. Bandung : Alfabeta.

Suranti, N. M. Y., Gunawan, G., \& Sahidu, H. (2016). Pengaruh Model Project Based Learning Berbantuan Media Virtual Terhadap Penguasaan Konsep Peserta didik pada Materi Alat-alat Optik. Jurnal Pendidikan Fisika dan Teknologi,2(2), $73-$ 79.

Trianto. 2011. Model Pembelajaran Terpadu. Jakarta: Bumi Aksara. 